\title{
Quantifying the effect of aerosol on vertical velocity and effective terminal velocity in warm convective clouds
}

\author{
Guy Dagan, Ilan Koren, and Orit Altaratz \\ Department of Earth and Planetary Sciences, the Weizmann Institute of Science, Rehovot 76100, Israel
}

Correspondence: Ilan Koren (ilan.koren@weizmann.ac.il)

Received: 14 January 2018 - Discussion started: 29 January 2018

Revised: 26 April 2018 - Accepted: 27 April 2018 - Published: 15 May 2018

\begin{abstract}
Better representation of cloud-aerosol interactions is crucial for an improved understanding of natural and anthropogenic effects on climate. Recent studies have shown that the overall aerosol effect on warm convective clouds is non-monotonic. Here, we reduce the system's dimensions to its center of gravity (COG), enabling distillation and simplification of the overall trend and its temporal evolution. Within the COG framework, we show that the aerosol effects are nicely reflected by the interplay of the system's characteristic vertical velocities, namely the updraft $(w)$ and the effective terminal velocity $(\eta)$. The system's vertical velocities can be regarded as a sensitive measure for the evolution of the overall trends with time. Using a bin-microphysics cloud-scale model, we analyze and follow the trends of the aerosol effect on the magnitude and timing of $w$ and $\eta$, and therefore the overall vertical COG velocity. Large eddy simulation (LES) model runs are used to upscale the analyzed trends to the cloud-field scale and study how the aerosol effects on the temporal evolution of the field's thermodynamic properties are reflected by the interplay between the two velocities. Our results suggest that aerosol effects on air vertical motion and droplet mobility imply an effect on the way in which water is distributed along the atmospheric column. Moreover, the interplay between $w$ and $\eta$ predicts the overall trend of the field's thermodynamic instability. These factors have an important effect on the local energy balance.
\end{abstract}

\section{Introduction}

Clouds are key players in the Earth's climate system via their influence on the energy balance (Baker and Peter, 2008; Trenberth et al., 2009) and hydrological cycle. Of all of the anthropogenic effects on climate, aerosol's effect on clouds remains one of the most uncertain (Boucher et al., 2013). In warm clouds, aerosol acts as cloud condensation nuclei $(\mathrm{CCN})$ around which droplets can form, and therefore aerosol amount and properties determine the initial number of droplets and their size distribution (Squires, 1958; Rosenfeld and Lensky, 1998; Andreae et al., 2004; Koren et al., 2005). The initial droplet concentration affects cloud dynamics via microphysical and dynamical feedback throughout their lifetime. For example, the onset of significant collision events between droplets in polluted clouds, which are initially smaller and more numerous than in clean clouds (Squires, 1958), is delayed (Gunn and Phillips, 1957; Rosenfeld, 1999, 2000; Squires, 1958; Warner, 1968). This delay can have opposing effects on cloud development by increasing both the water loading (which reduces cloud buoyancy and vertical development) and the latent heat release resulting from the longer and more efficient condensation (increasing cloud buoyancy and vertical development) (Dagan et al., 2015a, b; Pinsky et al., 2013; Koren et al., 2014). We note that, often, these opposing effects act at different stages of the cloud's lifetime, further complicating the prediction of overall trends.

Air vertical velocities $(w)$ are among the key processes driving convective clouds. The intensity, duration and characteristic size of the updrafts determine the convective clouds' properties. In addition, the clouds' vertical velocity affects the distribution of water along the atmospheric column, thereby having a strong effect on radiation (Koren et al., 2010) and heat balance (Khain et al., 2005). Although previous studies have focused on deep convective clouds, these effects are expected to be significant in warm convective clouds as well. Moreover, warm processes serve as the initial and 
boundary conditions for mixed-phase processes in deep convective clouds, and therefore gaining a better process understanding of the warm phase is essential for understanding the deeper systems (Chen et al., 2017).

The system has another characteristic velocity that measures droplet mobility. This velocity, defined as the effective terminal velocity $(\eta)$, measures the weighted-by-mass terminal velocity of all hydrometeors within a given volume and therefore defines the falling velocity of the volume's center of gravity (COG) (Koren et al., 2009, 2015) compared to the air vertical velocity. Smaller droplets imply smaller $|\eta|$ (higher mobility) and therefore less deviation from the surrounding air movement. Since $\eta$ is always negative, smaller $|\eta|$ implies that, per a given air updraft, the collective liquid water mass will be carried up higher in the atmosphere. The movement of the COG compared to the surface, defined as $V_{\mathrm{COG}}$, is the vector sum of the two velocities: $V_{\mathrm{COG}}=w-|\eta|$.

$V_{\mathrm{COG}}$ has recently been shown to be a good measure for the temporal evolution of thermodynamic instability in cloud fields (Dagan et al., 2016). $V_{\text {COG }}$ represents the vertical movement of liquid water, which is downgradient of the net condensation-minus-evaporation profile. A negative $V_{\mathrm{COG}}$ implies net transport of the liquid water from the cloudy layer to the sub-cloud layer. This holds true for clean (low aerosol concentration) precipitating cases (Dagan et al., 2016), in which the water that condenses in the cloudy layer sediments down to the sub-cloud layer where it partially evaporates. The net condensation in the cloudy layer and the net evaporation in the sub-cloud layer produce a decrease in the thermodynamic instability with time. On the other hand, for the polluted non-precipitating cases, $V_{\mathrm{COG}}$ is positive, indicating that the net liquid water movement is upward. The water that is being condensed in the lower part of the cloudy layer is transported upward and evaporates in the upper cloudy and inversion layers (Dagan et al., 2016). The end result of this vertical condensation-minus-evaporation profile is an increase in thermodynamic instability with time.

Khain et al. (2005) used a two-dimensional cloud model with spectral (bin) microphysics to study the aerosol effect on deep convective cloud dynamics. They concluded that one of the reasons for comparatively low $w$ in clean maritime convective clouds compared to polluted continental ones is the rapid creation of raindrops. This increases the liquid water loading in the lower part of the cloud, thereby reducing buoyancy. They also claimed that the delayed raindrop production in the continental cloud increases the duration of the diffusion droplet growth stage, which, in turn, increases the latent heat release by condensation.

Seigel (2014) showed an increase in $w$ with increasing aerosol loading in the cloud core in numerical simulations of a warm convective cloud field. He also showed a decrease in cloud size under polluted conditions due to increased mixing between the clouds and their dry environment driven by stronger evaporation of smaller droplets in polluted cases.
It has been recently shown (Dagan et al., 2015a, b, 2017) that, under given environmental conditions, warm convective clouds have an optimal aerosol concentration $\left(N_{\mathrm{op}}\right)$ with respect to their macrophysical properties (such as total mass and cloud top height) and total surface rain yield. For concentrations smaller than $N_{\mathrm{op}}$, the cloud can be considered as aerosol limited (Koren et al., 2014; Reutter et al., 2009), and an increase in the mean cloud properties with aerosol loading can be expected due to an increase in the condensation efficiency and droplet mobility (Koren et al., 2015; Dagan et al., 2015a, 2017). Suppressive processes such as enhanced entrainment and water loading take over when the concentrations are higher than $N_{\mathrm{op}}$ and reverse the trend. It has also been shown that the value of $N_{\mathrm{op}}$ depends heavily on the environmental conditions (thermodynamic conditions that support deeper clouds would have a larger $N_{\text {op }}$ ).

In this work, a bin-microphysics cloud model and large eddy simulation (LES) of a cloud field were used to explore how changes in aerosol concentration affect $w$ and $\eta$; the interplay between them; and, as a result, the height of the COG in warm convective clouds (Koren et al., 2009).

\section{Methodology}

\subsection{Single-cloud model}

The Tel Aviv University axisymmetric nonhydrostatic cloud model (TAU-CM) with detailed treatment of cloud microphysics (Reisin et al., 1996; Tzivion et al., 1994) was used. The included warm microphysical processes were nucleation of droplets, condensation and evaporation, collisioncoalescence, breakup and sedimentation. The microphysical processes were formulated and solved using the method of moments (Tzivion et al., 1987).

The background aerosol size distribution used here represents a clean maritime environment (Jaenicke, 1988). The aerosols are assumed to be composed of $\mathrm{NaCl}$. The different aerosol concentrations $\left(25,500\right.$ and $10000 \mathrm{~cm}^{-3}$, denoted hereafter as $25 \mathrm{CCN}, 500 \mathrm{CCN}$ and $10000 \mathrm{CCN}$, respectively) and size distributions are identical to those used in Dagan et al. (2015a). To study the involved processes, we used a wide range of aerosol loading conditions, from extremely pristine to extremely polluted. These specified three aerosol concentrations represent conditions which are below, around and above the optimal aerosol concentration $\left(N_{\mathrm{op}}\right)$. To avoid giant $\mathrm{CCN}$ effects, the aerosol size distribution was cut at $1 \mu \mathrm{m}$ (Feingold et al., 1999; Yin et al., 2000; Dagan et al., 2015b).

The model resolution was set to $50 \mathrm{~m}$, in both the vertical and horizontal directions, and the time step to $1 \mathrm{~s}$. The initial conditions were based on theoretical atmospheric profiles that describe a tropical environment (Malkus, 1958) (see profile T1RH2 in Fig. 1 in Dagan et al., 2015a). They consisted of a well-mixed sub-cloud layer between 0 and $1000 \mathrm{~m}$, a conditionally unstable cloudy layer $\left(6.5^{\circ} \mathrm{C} \mathrm{km}^{-1}\right)$ between 


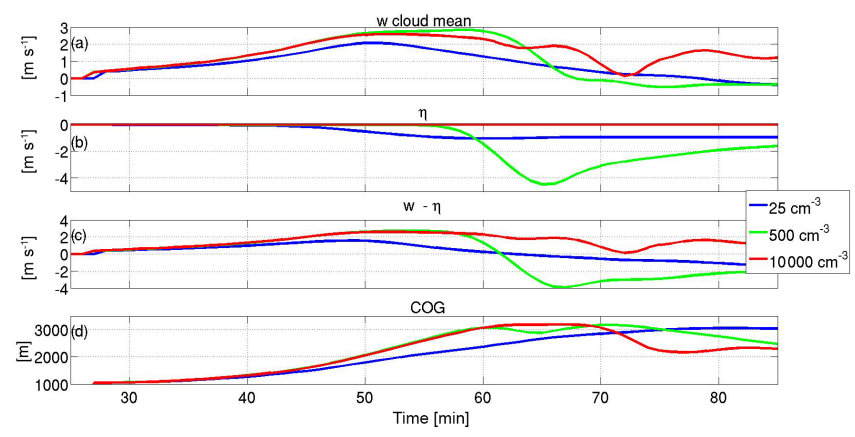

Figure 1. (a) Mean vertical velocity $(w)$, (b) mean effective terminal velocity $(\eta)$, (c) mean vertical velocity plus effective terminal velocity, and (d) cloud center of gravity (COG) as a function of time for three different aerosol concentrations.

1000 and $4000 \mathrm{~m}$, and an overlying inversion layer (temperature gradient of $2{ }^{\circ} \mathrm{C}$ over $50 \mathrm{~m}$ ). The relative humidity (RH) in the cloudy (inversion) layer was $90 \%(30 \%)$. The results presented here were examined for a few different sets of initial conditions (different inversion-base heights and cloudy layer RH). Although for different initial atmospheric conditions the transition between aerosol invigoration to suppression occurs at different aerosol concentration (Dagan et al., 2015a), the conclusions were found to be general for different sets of initial conditions.

To examine the effect of aerosols on the entire cloud, the properties presented in this work are cloud mean values weighted by the liquid water mass in each grid cell. Cloudy grid cells were defined as cells with liquid water content larger than $0.01 \mathrm{~g} \mathrm{~kg}^{-1}$. The cloud's COG (Koren et al., 2009) was calculated as

$\mathrm{COG}=\frac{\Sigma m_{i} z_{i}}{\Sigma m_{i}}$,

where $m_{i}$ and $z_{i}$ are the mass $(\mathrm{kg})$ and height (m) of grid cell $i$, respectively.

The $\eta$ (effective terminal velocity) was calculated according to Koren et al. (2015):

$\eta=\frac{\Sigma V t_{j} m_{j} n_{j}}{\Sigma m_{j} n_{j}}$

where $V t_{j}, m_{j}$ and $n_{j}$ are the terminal velocity $\left(\mathrm{m} \mathrm{s}^{-1}\right)$, mass $(\mathrm{kg})$ and concentration $\left(\mathrm{cm}^{-3}\right)$ of droplets in bin $j$, respectively. This was calculated for all cloudy grid cells.

To be consistent with the COG point of view, the mean air vertical $(w)$ was calculated as a mean weighted by the liquid mass:

$w=\frac{\sum m_{i} w_{i}}{\sum m_{i}}$.

The axisymmetric model uses a geometry that is only a simplification and idealization of a full 3-D flow and does not account, for example, for wind shear and processes acting on larger scales like clouds' effect on the environmental conditions with time. To account for these processes, we used 3-D cloud-field scale simulations as well (see Sect. 2.2 below).

\subsection{Cloud-field simulations}

We used the System for Atmospheric Modeling (SAM) LES model (Khairoutdinov and Randall, 2003) with a binmicrophysics scheme (Khain and Pokrovsky, 2004) to simulate the BOMEX (Barbados Oceanographic and Meteorological EXperiment) warm cumulus case study (Holland and Rasmusson, 1973; Siebesma et al., 2003). The horizontal resolution was set to $100 \mathrm{~m}$ and the vertical resolution to $40 \mathrm{~m}$. The domain size was $12.8 \times 12.8 \times 4.0 \mathrm{~km}^{3}$ and the time step was $1 \mathrm{~s}$. We ran the model for $16 \mathrm{~h}$, but the statistical analysis included only the last $14 \mathrm{~h}$ of the simulation. We used eight different aerosol concentrations: 5, 25, 50, 100, 250, 500, 2000 and $5000 \mathrm{~cm}^{-3}$. We used a marine background aerosol size distribution (Jaenicke, 1988). Further details about the simulations can be found in Dagan et al. (2017).

\section{Results and discussion}

\subsection{Single cloud: vertical velocity and effective terminal velocity}

Starting from the single-cloud scale, we first followed the entire cloud mean $w$ (Eq. 3), mean $\eta$ (Eq. 2), mean $V_{\mathrm{COG}}$ and COG height (Eq. 1) as a function of time for the three different levels of aerosol loading $\left(25,500\right.$ and $\left.10000 \mathrm{~cm}^{-3}\right)$. From an early stage of the cloud's evolution, the cleanest cloud $(25 \mathrm{CCN})$ had the lowest COG. This was a result of the lower $w$ (Fig. 1a) and larger absolute value of the negative $\eta$ (caused by the initially larger droplets, Fig. 1b), which together cause a lower $V_{\mathrm{COG}}$ (Fig. 1c). At the early stages of the polluted clouds, the 500CCN and 10000CCN COG moved upward at the same rate. After about $60 \mathrm{~min}$ of simulation, the 500CCN's COG started to decrease while the 10000CCN's COG remained relatively high. This trend could not be explained by the cloud's mean $w$ (Fig. 1a). The $500 \mathrm{CCN}$ 's $w$ was higher than that of the 10000CCN during the period between 50 and 63 min of simulation. Without considering the effect of $\eta$ on the COG, one would expect that the 500CCN's COG would be higher than that of the $10000 \mathrm{CCN}$. The 500CCN had lower (more negative) values of $\eta$ than the $10000 \mathrm{CCN}$, which decreased the height of its COG compared to the $10000 \mathrm{CCN}$. These larger negative values of $\eta$ in the 500CCN were due to the rain that developed from this cloud (the rain from the $10000 \mathrm{CCN}$ is negligible), which led to lower mobility (lower ability to move with the ambient air, Koren et al., 2015).

We note that the vertical change in the COG height is determined by changes in the vertical distribution of water mass due to microphysical processes like condensation, evapora- 


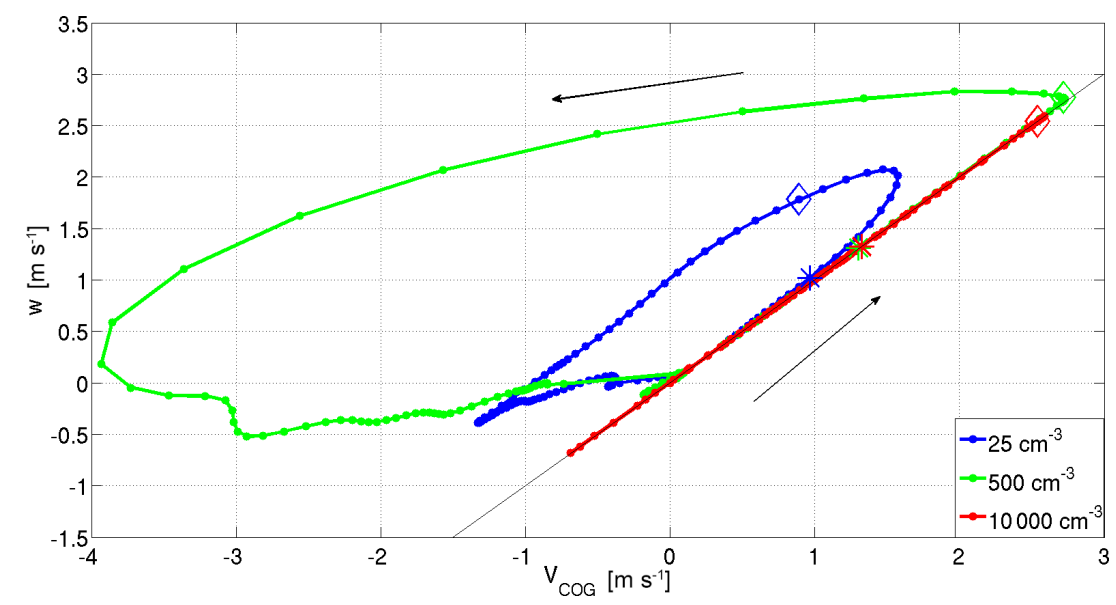

Figure 2. Cloud evolution on the phase space span by $w$ vs. $V_{\mathrm{COG}}$. The arrows mark the direction of the trajectories and the thin black line is the $1: 1$ line. Stars and diamonds denote $t=40 \mathrm{~min}$ and $55 \mathrm{~min}$ of the simulation, respectively.

tion and removal of mass by rain (in addition to movement according to $V_{\mathrm{COG}}$ ). Hence, in some parts of the simulations the $V_{\mathrm{COG}}$ was not a perfect predictor of the COG evolution. This is especially true when rain and evaporation are strong i.e., toward the end of the clouds' lifetime.

Figure 1 demonstrates the importance of the aerosol effect on both $w$ and $\eta$ in determining the COG height. Figure 2 presents the evolution of the clouds on the phase space span by $w$ vs. $V_{\mathrm{COG}}$. All clouds began their evolution on the $1: 1$ line. This means that at the early stages of the cloud's evolution, $\eta \sim 0$ and hence $V_{\mathrm{COG}} \sim w$. After about $40 \mathrm{~min}$ of simulation, the cleanest cloud's (25CCN) trajectory began to deviate from the $1: 1$ line to the left, demonstrating an increase in $|\eta|$ and hence lower droplet mobility. The deviation from the $1: 1$ line occurred later (at about $t=55 \mathrm{~min}$ of simulation) in the more polluted simulation $(500 \mathrm{CCN})$, whereas for the most polluted cloud $(10000 \mathrm{CCN})$, the lack of significant collision-coalescence and rain production resulted in evolution on the $1: 1$ line throughout the cloud's lifetime. This delay in the deviation from the $1: 1$ line (increasing the time for which $\eta \sim 0$ ) demonstrates the increase in droplet mobility with aerosol loading. The longer period for which $\eta \sim 0$ in the polluted cases enables the water mass to be pushed higher into the atmosphere and hence (together with the increase in the air vertical velocity, Fig. 1a) to cause cloud invigoration by the aerosol (Koren et al., 2015).

\subsection{LES results: aerosol effect on the vertical velocity and effective terminal velocity in cloud fields}

Shifting our view from the single-cloud scale to the cloudfield scale adds another layer of complexity as clouds affect the way in which the whole field's thermodynamics evolve with time. Moreover, 3-D simulations account for the effect of wind shear. Aerosol concentration has recently been shown to determine the trend of this evolution (Dagan et al.,
2016, 2017). Clean precipitating clouds act to consume the initial instability that created them by warming the cloudy layer (in which there is net condensation) and cooling the sub-cloud layer (by rain evaporation). On the other hand, polluted non-precipitating clouds act to increase the field's instability by cooling and moistening the upper cloudy and inversion layers.

Figure 3 presents the domain's mean $w$ (in both space and time, weighted by the liquid water mass to be consistent with the COG view; see Eq. 3 above) vs. the domain mean $\eta$. The color coding in Fig. 3 denotes the different aerosol concentrations. In agreement with previous studies (Saleeby et al., 2015; Seigel, 2014), an increase in aerosol loading yielded an increase in $w$. In our simulations, this increase is driven by larger latent heat contribution to the cloud's buoyancy due to the increased condensation efficiency (Dagan et al., 2015a, 2017; Koren et al., 2014; Pinsky et al., 2013; Seiki and Nakajima, 2014) and thermodynamic instability (Dagan et al., 2016, 2017). In parallel, aerosol shifts to smaller droplets (Squires, 1958) and reduces the magnitude of $\eta$, indicating better mobility of the smaller droplets (Koren et al., 2015). The outcome of these two effects (that work together to push the water mass higher in the atmosphere) is an increase in COG height with aerosol loading (Heiblum et al., 2016b; Dagan et al., 2017).

In the single-cloud-scale analysis (Sect. 3.1), we show how the timing of the evolution of the two velocities dictates the aerosol effect. Here, having many clouds in the field in different stages of their lifetimes, we first analyzed the bulk properties of the two velocities. With the intention of quantifying the relative contribution of the aerosol effect on the mean COG height by modulating $w$ and $\eta$, we plotted them one against the other for all of the simulations that differed in aerosol loading and for all clouds in the domain (Fig. 3a). For the entire simulation period, the $\eta$ vs. $w$ scatter plot resulted in an almost a straight line $\left(R^{2}=0.96\right)$ which was sorted by 

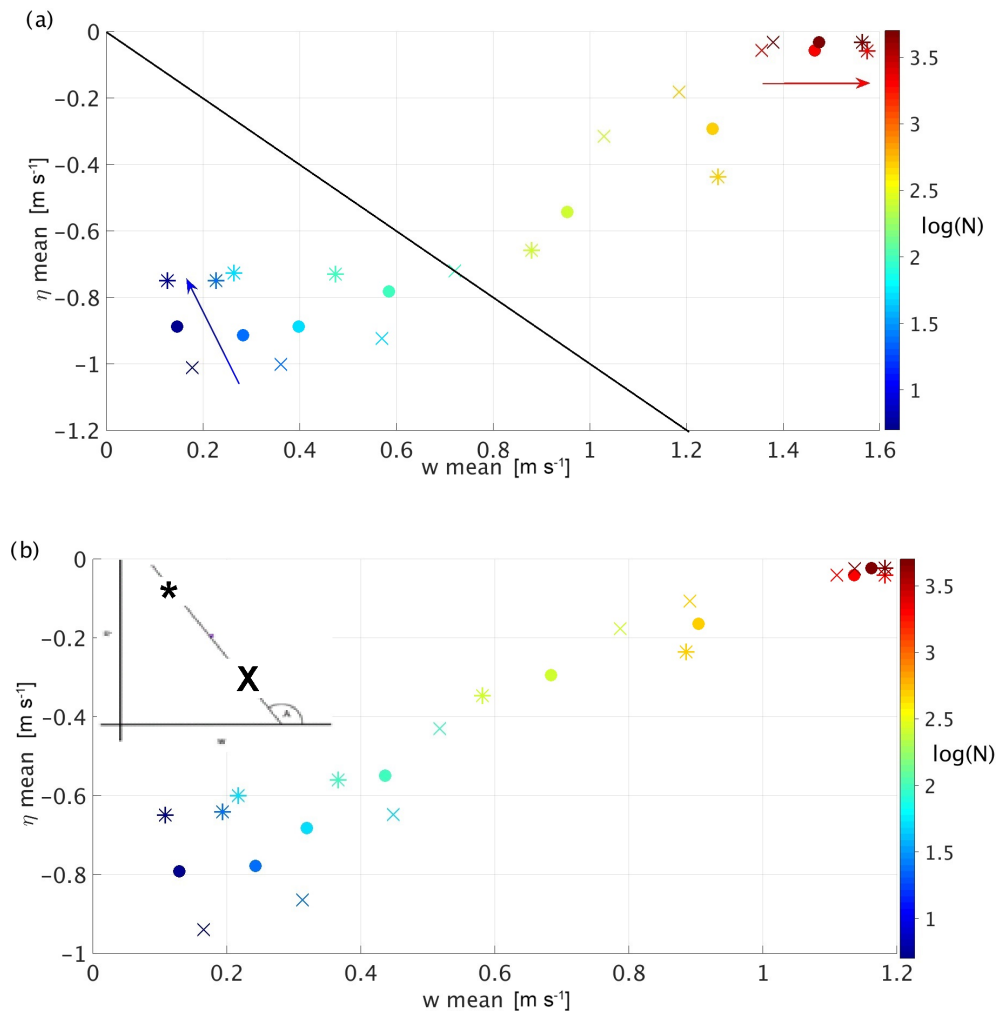

Figure 3. Temporal and spatial averages of the ambient air vertical velocity $(w)$ vs. effective terminal velocity $(\eta)$. Color coding denotes the different aerosol concentrations $\left(N\left[\mathrm{~cm}^{-3}\right]\right)$. Dots represent averages of the entire simulation data (excluding the first $2 \mathrm{~h}$ spin-up time). The $x$ and ${ }^{*}$ markers represent the first third ( 2 to $\left.6 \mathrm{~h} 40 \mathrm{~min}\right)$ and last third $(11 \mathrm{~h} 20 \mathrm{~min}$ to $16 \mathrm{~h}$ ) of the simulation period, respectively. (a) All clouds in the domain. (b) Only clouds in the growing stage. The black line in (a) is the zero-sum line for which $V_{\mathrm{COG}}=0$ (below the line $V_{\mathrm{COG}}<0$ and above it $V_{\mathrm{COG}}>0$ ). The angle $A$ that measures the $\eta$ vs. $w$ time trend per aerosol level is illustrated in the inset in (b).

aerosol concentration with a slope of 0.69 . This means that an increase in aerosol concentration that will result in a $1 \mathrm{~m} \mathrm{~s}^{-1}$ increase in mean $w$ will drive a decrease in the magnitude of $|\eta|$ by $0.69 \mathrm{~m} \mathrm{~s}^{-1}$. In other words, the relative contribution to the changes in the mean COG height in the domain caused by the increase in aerosol loading (Heiblum et al., 2016b; Dagan et al., 2017) during the entire simulation is $\sim 60 \%$ due to changes in $w$ and $\sim 40 \%$ due to changes in $\eta$.

To include the aerosol effect on the cloud-field thermodynamic properties, we divided the simulation period into three equal thirds (excluding the first $2 \mathrm{~h}$, each third of a period covered $4 \mathrm{~h}$ and $40 \mathrm{~min}$ ). The $x$ and * markers in Fig. 3a represent the first third ( $2 \mathrm{~h}$ to $6 \mathrm{~h} 40 \mathrm{~min}$ into the simulation) and last third ( $11 \mathrm{~h} 20 \mathrm{~min}$ to $16 \mathrm{~h}$ into the simulation), respectively. During the first third, the slope of $\eta$ vs. $w$ was steeper than the mean over the entire simulation (slope of 0.92 with $R^{2}=0.96$ ); during the last third, it was more gradual (slope of 0.47 with $R^{2}=0.87$ ). The almost $1: 1$ relation between $w$ and $\eta$ in the first third of the simulation period suggests a comparable contribution in determining the aerosol effect on mean COG height. However, the relative contribution of $\eta$ decreases as the simulation progresses, to about $1 / 3$ during the last third of the simulation period (compared with $2 / 3$ of $w)$.

The decrease in the $\eta$ vs. $w$ slopes toward the end of the simulations is driven by the changes in the thermodynamic instability. The increase in instability under polluted conditions produces an increase in mean $w$ (Dagan et al., 2016). Nevertheless, increased instability and deepening of the cloud layer are not sufficient to produce a significant amount of rain under the most polluted simulations and, hence, there is no increase in the magnitude of $\eta$. An increase in $w$ with no change in $\eta$ is manifested as a horizontal shift to the right on the $\eta$ vs. $w$ phase space (red arrow in Fig. 3a). On the other hand, the decreased instability under clean conditions produces a decrease in both mean $w$ and the rain amount (Dagan et al., 2017) and therefore in $|\eta|$ (blue arrow in Fig. 3a). The end result of the different changes in $w$ and $\eta$ under clean and polluted conditions is a decrease in the slope of $\eta$ vs. $w$ and, therefore, a decrease in the relative contribution of $\eta$ to the aerosol effect on the mean COG.

In Fig. 3a, the presented quantities are domain and time averages. Figure 1 shows that the relative contribution of $w$ and $\eta$ to the aerosol effect on COG height strongly depends on the stage of the cloud's evolution. The averaging in Fig. 3a 


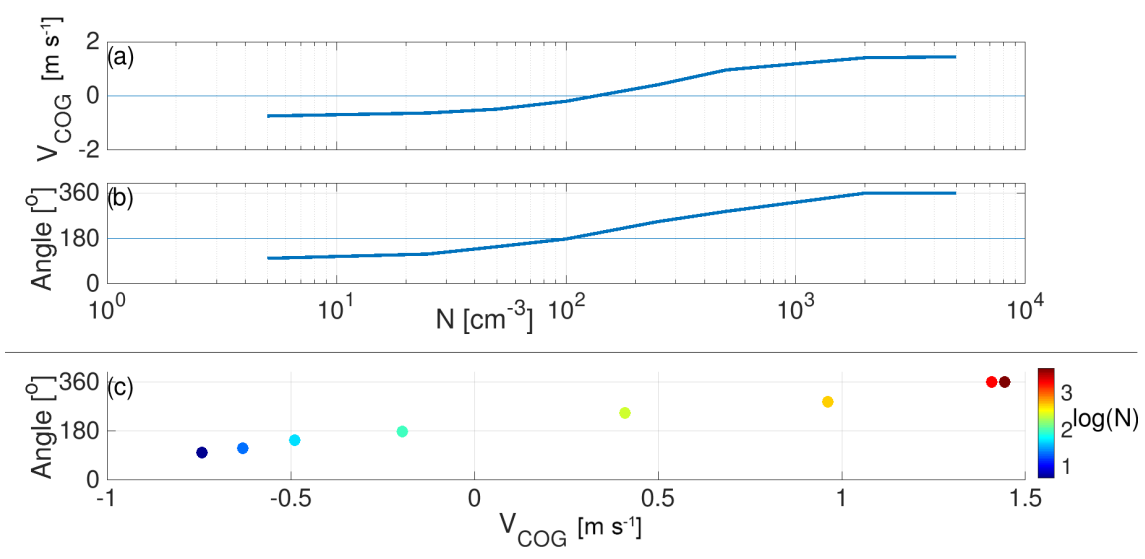

Figure 4. (a) The cloud field's mean value of $V_{\mathrm{COG}}$ and (b) the angle $A$ between the line that connects the first and last thirds of the simulation period and the $x$ axis on the $\eta$ vs. $w$ phase space for all clouds in the domain (Fig. 3a) as a function of aerosol loading. (c) $A$ vs. $V_{\mathrm{COG}}$. Color coding denotes the different aerosol concentrations $\left(N\left[\mathrm{~cm}^{-3}\right]\right)$.

Table 1. Linear regression slope on the $\eta$ vs. $w$ phase space for the different periods of the simulations for all clouds and growing-stage clouds in the domain. $R^{2}$ of the regression lines is presented in parentheses.

\begin{tabular}{lll}
\hline & All clouds & $\begin{array}{l}\text { Growing } \\
\text { clouds }\end{array}$ \\
\hline $\begin{array}{l}\text { Total simulation period } \\
(2-14 \mathrm{~h})\end{array}$ & $0.69(0.96)$ & $0.79(0.98)$ \\
$\begin{array}{l}\text { First period of simulation } \\
(2 \mathrm{~h}-6 \mathrm{~h} 40 \text { min into the simulation })\end{array}$ & $0.92(0.96)$ & $0.99(0.93)$ \\
$\begin{array}{l}\text { Last period of simulation } \\
(11 \mathrm{~h} 20 \text { min-16h into the simulation })\end{array}$ & $0.47(0.87)$ & $059(0.98)$ \\
\hline
\end{tabular}

mixes many clouds at different stages in their evolution and represents the effect on the mean COG in the domain. To further explore the relative contribution of the aerosol effect on $w$ and $\eta$ as a function of the cloud-evolution stage, we used a cloud-tracking algorithm (Heiblum et al., 2016a). We identified the growing stage of the clouds as the stage for which the cloud top ascends. Figure $3 b$ presents the $\eta$ vs. $w$ phase space only for clouds in their growing stage. Table 1 presents the slopes of the linear regression lines for the entire simulation time and for the different thirds of the simulation period. As was shown for all cloud, the $\eta$ contribution to the aerosol effect on the COG height decreases with time (compared to $w$ ) also for the growing clouds (see the decrease in the slope with time). This, again, was due to the changes in thermodynamic conditions.

As shown for the cloud scale, one of the most notable aerosol effects can be viewed as delaying the onset of significant collection processes in the polluted clouds (Koren et al., 2015) and therefore delaying the increase in $|\eta|$ values early in the cloud's lifetime. Therefore, during the growing stage, the relative contribution of $\eta$ was higher (Fig. 3b) as compared to all clouds (Fig. 3a). This was demonstrated by the increasing slope of the $\eta$ vs. $w$ phase space during the growing stage (Table 1).

To quantify the evolution of the thermodynamic instability with time as a function of aerosol loading (on a cloudfield scale), we looked at the time trends in the $\eta$ vs. $w$ phase space. We defined the angle $A$ as the angle between the time trend points on the $\eta$ vs. $w$ phase space per given aerosol loading (the line that connects the first and last thirds of the simulation and the $x$ axis on the $\eta$ vs. $w$ phase space; see schematic definition of $A$ in Fig. $3 \mathrm{~b}$ ). We note that $A$ rotates counterclockwise with increasing aerosol loading (Fig. 3a). It starts as $\sim 100^{\circ}$ for the cleanest simulation and monotonically increases with aerosol loading to $\sim 360^{\circ}$ for the most polluted simulations (Fig. 4b). A between $90^{\circ}$ and $180^{\circ}$ (as shown for clean cases, Fig. 4b) represents a decrease in both $w$ and $|\eta|$ and hence a decrease in the thermodynamic instability with time. A between 270 and $360^{\circ}$, on the other hand (as shown for the most polluted cases, Fig. 4b), represents an increase in both $w$ and $|\eta|$ and hence an increase in the thermodynamic instability with time.

The sign of $V_{\mathrm{COG}}$ has been shown to predict the evolution of thermodynamic instability (Dagan et al., 2016). Thus, correlations between $A$ and $V_{\mathrm{COG}}$ are expected. Figure 4 presents $V_{\mathrm{COG}}$ (Fig. 4a) and $A$ (Fig. 4b) as a function of the aerosol loading, as well as $A$ vs. $V_{\mathrm{COG}}$ (Fig. 4c). Figure 4a and $\mathrm{b}$ demonstrates that both $V_{\mathrm{COG}}$ and $A$ increase monotonically with aerosol loading following a similar trend. $V_{\mathrm{COG}}$ and $A$ cross the 0 and $180^{\circ}$ lines, respectively, at similar aerosol concentrations, representing the transition between consumption and production of the thermodynamic instability (Dagan et al., 2016). Figure $4 \mathrm{c}$ further demonstrates an almost perfect linear correlation $\left(R^{2}=0.99\right)$ between $V_{\mathrm{COG}}$ and $A$ sorted by aerosol concentration. 


\subsection{Summary}

Clouds form a complex system in which microphysical and dynamical processes are tightly linked and modulated by the thermodynamic properties of the environment. In turn, on the cloud-field scale, clouds affect the field's thermodynamic conditions. The aerosol effect on the droplet size distribution therefore affects all of the above. Better process-level understanding of the aerosol effect on cloud and rain properties in the case of warm convective clouds is essential for improving our understanding of the climate system. In this study, our aim was to better understand and quantify the aerosol effect on the air vertical velocity and droplet terminal velocity. Both characteristic vertical velocities' quantities modulate the distribution of water along the atmospheric column and hence affect the radiation (Koren et al., 2010) and heat balance (Khain et al., 2005). The findings presented here for the single-cloud and cloud-field scales could be used in future works to better represent cloud-aerosol interactions in coarser-resolution models (like climate models) as they provide a compact way to represent aerosol effect on the liquid water vertical mass flux and clouds' effect on the thermodynamic conditions.

Analyzing the two characteristic velocities on the cloud scale allows separation, as a first approximation, between the aerosol effects on condensation and evaporation efficiencies (reflected by the magnitude of $w$ ) and those on droplet mobility (reflected by the inverse magnitude of $\eta$ ). The magnitudes of $w$ and $\eta$ act in opposite ways; i.e., stronger $w$ and smaller $|\eta|$ imply more efficient transport of liquid water to the upper atmosphere. We use their sum, defined as $V_{\mathrm{COG}}$, to estimate the overall effect on the COG's vertical movement. Single-cloud analysis showed the timing of this interplay and how each velocity affects the COG elevation. It showed that the invigorating aerosol effect can be viewed mostly at the early stages of cloud development, when an increase in aerosol loading enhances the condensation efficiency (reflected as higher $w$ levels) and delays the onset of significant collection processes (reflected as a delay in the sharp increase in $\eta$ ). Both act to transfer liquid water higher into the atmosphere (Koren et al., 2015). Later, as the cloud dissipates, the "payment" is viewed as enhanced evaporation, and, if the cloud manages to reach the significant collectionprocess stage, then the surface rain is stronger (expressed as a sharp increase in $|\eta|)$.

Similar to the single-cloud case, the cloud-field (LES) results (that unlike the single-cloud simulations account for 3$D$ processes such as wind shear) demonstrated an increase in $w$ and decrease in the magnitude of $\eta$ (less negative $\eta$ ) with aerosol loading, both yielding a higher COG. We analyzed the bulk properties of the two velocities for the entire simulation time (14 h) and for all clouds in the domain and showed that the relative contribution of the aerosol effect on $w$ and $\eta$ in determining COG evolution is comparable (60 and $40 \%$, respectively). However, at the beginning of the simulation, this ratio was almost $1: 1$, and the relative contribution of $\eta$ decreased with time. Such temporal changes in the $\eta$ vs. $w$ slope indicate changes in the thermodynamic properties of the field (Dagan et al., 2016). Increasing thermodynamic instability under polluted conditions results in an increase in $w$, while the decreasing instability under clean condition results in a decrease in rain amount and, hence, in $\eta$. Both trends act to reduce the slope. We have defined the angle $A$, which represents the evolution of the thermodynamic conditions with time. A can serve as a compact measure of the thermodynamic instability evolution in future observational or numerical studies that quantify $w$ and $\eta$.

Using a cloud-tracking algorithm, we identified the growing stage of the clouds and examined the relative contribution of the aerosol effect on COG height by modulating $w$ and $\eta$ during this stage. We showed that the relative contribution of the aerosol effect on $\eta$ is larger during the growing stage (for which aerosol loading acts to maintain lower $|\eta|$ for a longer time) compared to the mature and dissipating stages, thereby strengthening the argument that most of the aerosol invigoration effect occurs early in the cloud's evolution (Koren et al., 2015).

Data availability. No data sets were used in this article.

Competing interests. The authors declare that they have no conflict of interest.

Acknowledgements. This research was supported by the Minerva Foundation with funding from the Federal German Ministry of Education and Research and the De Botton Center for Marine Science.

Maria Cristina Facchini

Reviewed by: two anonymous referees

\section{References}

Andreae, M. O., Rosenfeld, D., Artaxo, P., Costa, A. A., Frank, G. P., Longo, K. M., and Silva-Dias, M. A. F.: Smoking rain clouds over the Amazon, Science, 303, 1337-1342, https://doi.org/10.1126/science.1092779, 2004.

Baker, M. B. and Peter, T.: Small-scale cloud processes and climate, Nature, 451, 299-300, https://doi.org/10.1038/nature06594, 2008.

Boucher, O., Randall, D., Artaxo, P., Bretherton, C., Feingold, G., Forster, P., Kerminen, V., Kondo, Y., Liao, H., and Lohmann, U.: Clouds and aerosols, Clim. Change, 571-657, 2013.

Chen, Q., Koren, I., Altaratz, O., Heiblum, R. H., Dagan, G., and Pinto, L.: How do changes in warm-phase microphysics affect deep convective clouds?, Atmos. Chem. Phys., 17, 9585-9598, https://doi.org/10.5194/acp-17-9585-2017, 2017.

Dagan, G., Koren, I., and Altaratz, O.: Competition between core and periphery-based processes in warm convective clouds - from 
invigoration to suppression, Atmos. Chem. Phys., 15, 27492760, https://doi.org/10.5194/acp-15-2749-2015, 2015a.

Dagan, G., Koren, I., and Altaratz, O.: Aerosol effects on the timing of warm rain processes, Geophys. Res. Lett., 42, 4590-4598, https://doi.org/10.1002/2015GL063839, 2015b.

Dagan, G., Koren, I., Altaratz, O., and Heiblum, R. H.: Aerosol effect on the evolution of the thermodynamic properties of warm convective cloud fields, Sci. Rep., 6, 38769, https://doi.org/10.1038/srep38769, 2016.

Dagan, G., Koren, I., Altaratz, O., and Heiblum, R. H.: Timedependent, non-monotonic response of warm convective cloud fields to changes in aerosol loading, Atmos. Chem. Phys., 17, 7435-7444, https://doi.org/10.5194/acp-17-7435-2017, 2017.

Feingold, G., Cotton, W. R., Kreidenweis, S. M., and Davis, J. T.: The impact of giant cloud condensation nuclei on drizzle formation in stratocumulus: Implications for cloud radiative properties, J. Atmos. Sci., 56, 4100-4117, https://doi.org/10.1175/15200469(1999)056<4100:tiogcc> 2.0.co;2, 1999.

Gunn, R. and Phillips, B.: An experimental investigation of the effect of air pollution on the initiation of rain, J. Meteorol., 14, 272-280, 1957.

Heiblum, R. H., Altaratz, O., Koren, I., Feingold, G., Kostinski, A. B., Khain, A. P., Ovchinnikov, M., Fredj, E., Dagan, G., and Pinto, L.: Characterization of cumulus cloud fields using trajectories in the center of gravity versus water mass phase space: 1 . Cloud tracking and phase space description, J. Geophys. Res.Atmos., 121, 6336-6355, 2016a.

Heiblum, R. H., Altaratz, O., Koren, I., Feingold, G., Kostinski, A. B., Khain, A. P., Ovchinnikov, M., Fredj, E., Dagan, G., and Pinto, L.: Characterization of cumulus cloud fields using trajectories in the center-of-gravity vs. water mass phase space: 2 . Aerosol effects on warm convective clouds, J. Geophys. Res.Atmos., 121, 6356-6373, 2016b.

Holland, J. Z. and Rasmusson, E. M.: Measurements of the atmospheric mass, energy, and momentum budgets over a 500kilometer square of tropical ocean, Mon. Weather Rev., 101, 4455, 1973.

Jaenicke, R.: Aerosol physics and chemistry, Landolt-Börnstein Neue Serie, 4b, 391-457, 1988.

Khain, A. and Pokrovsky, A.: Simulation of effects of atmospheric aerosols on deep turbulent convective clouds using a spectral microphysics mixed-phase cumulus cloud model. Part II: Sensitivity study, J. Atmos. Sci., 61, 2983-3001, https://doi.org/10.1175/jas-3281.1, 2004.

Khain, A., Rosenfeld, D., and Pokrovsky, A.: Aerosol impact on the dynamics and microphysics of deep convective clouds, Q. J. Roy. Meteorol. Soc., 131, 2639-2663, https://doi.org/10.1256/qj.04.62, 2005.

Khairoutdinov, M. F. and Randall, D. A.: Cloud resolving modeling of the ARM summer 1997 IOP: Model formulation, results, uncertainties, and sensitivities, J. Atmos. Sci., 60, 607-625, 2003.

Koren, I., Kaufman, Y. J., Rosenfeld, D., Remer, L. A., and Rudich, Y.: Aerosol invigoration and restructuring of Atlantic convective clouds, Geophys. Res. Lett., 32, L023187, https://doi.org/10.1029/2005gl023187, 2005.

Koren, I., Altaratz, O., Feingold, G., Levin, Z., and Reisin, T.: Cloud's Center of Gravity - a compact approach to analyze convective cloud development, Atmos. Chem. Phys., 9, 155-161, https://doi.org/10.5194/acp-9-155-2009, 2009.
Koren, I., Remer, L. A., Altaratz, O., Martins, J. V., and Davidi, A.: Aerosol-induced changes of convective cloud anvils produce strong climate warming, Atmos. Chem. Phys., 10, 5001-5010, https://doi.org/10.5194/acp-10-5001-2010, 2010.

Koren, I., Dagan, G., and Altaratz, O.: From aerosol-limited to invigoration of warm convective clouds, Science, 344, 1143-1146, 2014.

Koren, I., Altaratz, O., and Dagan, G.: Aerosol effect on the mobility of cloud droplets, Environ. Res. Lett., 10, 104011, https://doi.org/10.1088/1748-9326/10/10/104011, 2015.

Malkus, J. S.: On the structure of the trade wind moist layer, https://doi.org/10.1575/1912/1065, 1958.

Pinsky, M., Mazin, I., Korolev, A., and Khain, A.: Supersaturation and diffusional droplet growth in liquid clouds, J. Atmos. Sci., 70, 2778-2793, 2013.

Reisin, T., Levin, Z., and Tzivion, S.: Rain Production in Convective Clouds As Simulated in an Axisymmetric Model with Detailed Microphysics. Part I: Description of the Model, J. Atmos. Sci., 53, 497-519, https://doi.org/10.1175/15200469(1996)053<0497:RPICCA>2.0.CO; 2, 1996.

Reutter, P., Su, H., Trentmann, J., Simmel, M., Rose, D., Gunthe, S. S., Wernli, H., Andreae, M. O., and Pöschl, U.: Aerosol- and updraft-limited regimes of cloud droplet formation: influence of particle number, size and hygroscopicity on the activation of cloud condensation nuclei (CCN), Atmos. Chem. Phys., 9, 70677080, https://doi.org/10.5194/acp-9-7067-2009, 2009.

Rosenfeld, D.: TRMM observed first direct evidence of smoke from forest fires inhibiting rainfall, Geophys. Res. Lett., 26, 31053108, https://doi.org/10.1029/1999g1006066, 1999.

Rosenfeld, D.: Suppression of rain and snow by urban and industrial air pollution, Science, 287, 1793-1796, https://doi.org/10.1126/science.287.5459.1793, 2000.

Rosenfeld, D. and Lensky, I. M.: Satellite-based insights into precipitation formation processes in continental and maritime convective clouds, B. Am. Meteor. Soc., 79, 2457-2476, https://doi.org/10.1175/15200477(1998)079<2457:sbiipf>2.0.co;2, 1998.

Saleeby, S. M., Herbener, S. R., van den Heever, S. C., and L'Ecuyer, T.: Impacts of Cloud Droplet-Nucleating Aerosols on Shallow Tropical Convection, J. Atmos. Sci., 72, 1369-1385, 2015 .

Seigel, R. B.: Shallow Cumulus Mixing and Subcloud Layer Responses to Variations in Aerosol Loading, J. Atmos. Sci., 71, 2581-2603, 2014

Seiki, T. and Nakajima, T.: Aerosol effects of the condensation process on a convective cloud simulation, J. Atmos. Sci., 71, 833853, 2014.

Siebesma, A. P., Bretherton, C. S., Brown, A., Chlond, A., Cuxart, J., Duynkerke, P. G., Jiang, H., Khairoutdinov, M., Lewellen, D., and Moeng, C. H.: A large eddy simulation intercomparison study of shallow cumulus convection, J. Atmos. Sci., 60, 12011219, 2003.

Squires, P.: The microstructure and colloidal stability of warm clouds, Tellus, 10, 262-271, 1958.

Trenberth, K. E., Fasullo, J. T., and Kiehl, J.: Earth's global energy budget, B. Am. Meteor. Soc, 90, 311-323, 2009.

Tzivion, S., Feingold, G., and Levin, Z.: An efficient numerical solution to the stochastic collection equation, J. Atmos. Sci., 44, 3139-3149, 1987. 
Tzivion, S., Reisin, T., and Levin, Z.: Numerical simulation of hygroscopic seeding in a convective cloud, J. Appl. Meteorol., 33, 252-267, 1994.

Warner, J.: A reduction in rainfall associated with smoke from sugar-cane fires-An inadvertent weather modification?, J. Appl. Meteorol., 7, 247-251, 1968.
Yin, Y., Levin, Z., Reisin, T. G., and Tzivion, S.: The effects of giant cloud condensation nuclei on the development of precipitation in convective clouds - a numerical study, Atmos. Res., 53, 91-116, 2000 . 